\title{
Sex Differences in Severity, Social Functioning, Adherence to Treatment, and Cognition of Adolescents with Schizophrenia
}

\author{
Rodolfo Pérez-Garza, ${ }^{1}$ Gamaliel Victoria-Figueroa, ${ }^{2}$ and Rosa Elena Ulloa-Flores ${ }^{1}$ \\ ${ }^{1}$ Hospital Psiquiátrico Infantil, Mexico City, Mexico \\ ${ }^{2}$ Arete Proyectos, Mexico City, Mexico \\ Correspondence should be addressed to Rosa Elena Ulloa-Flores; rosaelena.ulloa@areteproyectos.com
}

Received 31 March 2016; Revised 10 July 2016; Accepted 23 August 2016

Academic Editor: Veena Kumari

Copyright ( 2016 Rodolfo Pérez-Garza et al. This is an open access article distributed under the Creative Commons Attribution License, which permits unrestricted use, distribution, and reproduction in any medium, provided the original work is properly cited.

Background. Previous studies have reported sex differences in the clinical presentation and outcome of adult patients with schizophrenia; the aim of present study was to compare the clinical characteristics, social functioning, adherence to treatment, and cognition of adolescents with this diagnosis in a six-month followup. Methods. A total of 87 adolescents with a DSM-IV diagnosis of schizophrenia or schizophreniform disorder were evaluated with the Positive and Negative Symptoms Scale (PANSS), the Matrics Consensus Cognitive Battery (MCCB), Personal and Social Performance Scale (PSP), and the Rating of Medication Influences (ROMI). Results. Both groups showed a similar improvement in all PANSS factors and in the PSP scores during the followup. Males better adhered to treatment. Females displayed better results in the area of social cognition $(F=6.3, \mathrm{df}=2,52$, and $p=0.003)$ and attention/vigilance $(F=8.3, \mathrm{df}=2,51$, and $p=0.001)$. Conclusions. Male and female adolescents showed similar clinical presentation and functioning but a different pattern of cognitive improvement and adherence to treatment. This trial is registered with Clinicaltrials.gov II3/02/0811.

\section{Introduction}

Few studies had examined gender differences in patients with schizophrenia. Highlights from these studies showed that males had an earlier onset [1], more negative symptoms, and a poorer functioning [2], while females showed a higher prevalence of paranoid subtype and more severe positive symptoms and a better outcome [3].

Regarding cognitive function, males were reported to exhibit more difficulties in emotion perception, verbal memory, and cognitive flexibility $[4,5]$. A more recent study on patients with first episode of psychosis reported that women obtained higher scores than men on a test of verbal memory, whereas men scored higher on a test of reaction time, visual memory, and planning, displaying a pattern similar to that reported on healthy individuals [6]. Follow-up studies showed similar rates of adherence to treatment [7] but a better outcome in females [8].

Adolescent onset schizophrenia is relatively common, with almost $30 \%$ of patients having an illness onset before they turn 18 years old. The male-female ratio for adolescent onset schizophrenia has been reported to be in the range of $1.4: 1$ to $2.2: 1$ in early epidemiological studies [9]. In adolescence, factors such as the increase of hormonal levels and the maturation of the structures and functions involved in the information processing could account for sex differences [10]. For example, a greater loss of cerebral gray matter during brain maturation in males or the protective role of the estrogens in females [11] may in turn affect fundamental aspects of the illness. Given the paucity of studies on this matter, we aimed to compare the clinical characteristics, social functioning, and cognition of male and female adolescents with schizophrenia and to analyze possible differences in early course and adherence to treatment during a six-month followup.

\section{Methods}

Male and female subjects, aged 12 to 17 years, were recruited from the Child Psychiatric Hospital in Mexico City. All 
met DSM-IV criteria for schizophrenia or schizophreniform disorder [12] based on a diagnostic semistructured interview. Exclusion criteria were active medical comorbidities, drug abuse, and pregnancy. The study was in compliance with the Helsinki declaration and was approved by the Institutional Review Board.

\subsection{Measures}

2.1.1. Diagnosis Was Confirmed with the Mini-International Neuropsychiatric Interview. Child and Adolescent Version (MINI KID): the MINI KID was designed as a structured diagnostic interview to assess short-term psychopathology of children and adolescents. It examines the presence of 23 psychiatric disorders at the present time and throughout life according to DSM-IV and ICD-10 criteria [13].

\subsubsection{The Positive and Negative Syndrome Scale (PANSS).} This scale evaluates the severity of symptoms through 30 items which are scored on 1 to 7 scale. A Spanish validated version was used [14] and the severity of symptoms was evaluated according to the five-factor dimensional model of schizophrenic symptoms (positive, negative, excitement, anxiety/depression, and cognitive) $[15,16]$.

2.1.3. The Personal and Social Performance Scale (PSP). This is a short instrument with a score of 1-100 points. Lowest values represent a lack of autonomy in the basic functioning, while the highest values reflect excellent performance. Scores are based on an evaluation of the four domains rated according to specific operational definitions: (a) socially useful activities, including work and study, (b) personal and social relationships, (c) self-care, and (d) disturbing and aggressive behaviors [17]. In Mexico, PSP validity was evaluated in 40 adolescent patients, obtaining good internal consistency, a positive correlation with C-GAS, and a negative correlation with the negative, excitement, and cognitive factors derived from PANSS and MCCB domains; it also showed good internal consistency and interrater reliability [18].

The adherence to treatment was defined in a dichotomous variable, assessing the patient's capability to follow the medical instructions [19].

2.1.4. Rating of Medication Influences (ROMI). This scale was created for the assessment of perceived influences on compliance with antipsychotic treatment. It is composed of 3 Likert-type subscales related to compliance (prevention, influence of others, and medication affinity) and 5 subscales related to noncompliance (denial/dysphoria, logistical problems, rejection of label, family influence, and negative therapeutic alliance) [20].

2.1.5. The Matrics Consensus Cognitive Battery (MCCB). This instrument is used to evaluate 7 cognitive domains affected by this disorder: speed of processing, attention-vigilance, working memory, verbal learning, visual learning, reasoning/ problem solving, and social cognition. The seventh domain, social cognition, was included given its promising nature as a mediator of neurocognitive effects on functional outcome [21]. MCCB performance has been examined in samples of healthy adolescents to determine age adapted standardization [22] and compare the cognitive abilities of psychotic adolescents with those of healthy controls $[23,24]$. The reliability was established before the study was developed on every scale using case vignettes and videotapes. Intraclass correlation coefficients $>0.70$ and $80 \%$ of agreement were achieved.

2.2. Procedures. Evaluations were completed at baseline and every three weeks until week 12 . PANSS and adherence to treatment were examined on each visit. ROMI was rated on week 3 , month 3 , and month 6 . Other scales were rated on month 3 and month 6 . All participants were on pharmacological treatment during the study.

2.3. Statistical Analysis. Demographic and clinical characteristics were examined using descriptive statistics. Univariate analysis included chi-square and Student's $t$-tests. The changes in PANSS and MCCB scores were assessed using repeated measures ANOVA adjusted for years of education. If a significant effect was detected, Bonferroni corrections for multiple comparisons were performed to examine the effect of gender, the effect of time, or the differences in change over time among the gender groups (interaction effect). Finally, the Pearson correlation coefficient was used to find the correlations between ROMI's items and adherence to treatment. Significance was set at $p<0.05$ for all tests. Analyses were run with SPSS 20.0 for Windows.

\section{Results}

3.1. General Description of the Sample. The sample included 87 Hispanic adolescents (69\% males), with a mean age of 14.9 $( \pm 1.5)$ years, and all were single. Most of them $(84 \%)$ were on their first episode of psychosis, their mean PANSS score was 98.6 ( \pm 21.5$)$, and their mean global PSP was $35.7( \pm 13.6)$. Men had a longer mean duration of illness and a lower frequency of first psychotic episode (Table 1).

3.2. Psychotic Symptoms and Functioning. Risperidone was the most frequent antipsychotic prescribed (86.7\% of males, $70.4 \%$ of females, $X^{2}=3.29, \mathrm{df}=1$, and $p=\mathrm{ns}$ ). There was a significant improvement in all PANSS factors during the followup (Table 2).

3.3. Cognitive Functioning. Both groups showed an improvement on cognitive functioning. Females showed better results in social cognition and attention/vigilance (Table 3).

3.4. Social Functioning. Both groups exhibited a poor social functioning on the baseline evaluation. In particular, a larger percentage of the male sample exhibited disturbing /aggressive behavior. The PSP subscales showed a significant improvement during the followup (Table 4). At the sixth month of evaluation the mean PSP global score was $60.5 \pm 17$ in males and $67.4 \pm 11.8$ in females. 
TABLE 1: Demographic and clinical characteristics of male and female patients.

\begin{tabular}{lccc}
\hline & Male $(N=60)$ & Female $(N=27)$ & Statistics \\
\hline Demographic characteristics & & & $t=0.59, \mathrm{df}=44, p=\mathrm{ns}$ \\
Mean age & $15.0 \pm 1.46$ & $14.78 \pm 1.69$ & $t=2.09, \mathrm{df}=85, p=0.04$ \\
Mean number of years of education & $7.98 \pm 1.74$ & $8.77 \pm 1.36$ & $t=1.8, \mathrm{df}=85, p=0.05$ \\
\hline Psychiatric history & $1.31 \pm 1.42$ & & $t=0.77, \mathrm{df}=63, \mathrm{~ns}$ \\
Mean duration of illness (years) & $13.69 \pm 2.11$ & $14.01 \pm 1.63$ & $X^{2}=4.45, \mathrm{df}=1, p=0.03$ \\
Mean age of illness onset & $78.3 \%(n=47)$ & $96.3 \%(n=26)$ & \\
First psychotic episode & &
\end{tabular}

TABLE 2: Repeated measures ANOVA for PANSS factors.

\begin{tabular}{|c|c|c|c|c|c|}
\hline & $\begin{array}{c}\text { Males } \\
\text { Mean (SD) }\end{array}$ & $\begin{array}{c}\text { Females } \\
\text { Mean (SD) }\end{array}$ & Time effect & Gender effect & Time $*$ gender effect \\
\hline \multicolumn{6}{|l|}{ Positive } \\
\hline Baseline* & $18.8(3.7)$ & $17.6(2.7)$ & \multirow{3}{*}{$F=119.95, \mathrm{df}=2,56, p<0.001$} & \multirow{3}{*}{$F=0.68, \mathrm{df}=1,56, p=\mathrm{NS}$} & \multirow{3}{*}{$F=0.02, \mathrm{df}=2,56, p=\mathrm{NS}$} \\
\hline Month 3 & $9.4(5.5)$ & $8.6(5.2)$ & & & \\
\hline Month 6 & $7.6(4.2)$ & $6.9(5.2)$ & & & \\
\hline \multicolumn{6}{|l|}{ Negative } \\
\hline Baseline* & $21(7.5)$ & $21.7(4.9)$ & \multirow{3}{*}{$F=41.35, \mathrm{df}=2,57, p<0.001$} & \multirow{3}{*}{$F=2.03, \mathrm{df}=1,57, p=\mathrm{NS}$} & \multirow{3}{*}{$F=0.76, \mathrm{df}=2,57, p=\mathrm{NS}$} \\
\hline Month 3 & $15.7(6.4)$ & $12.4(4.8)$ & & & \\
\hline Month 6 & $13.8(6.1)$ & $11.6(6.5)$ & & & \\
\hline \multicolumn{6}{|c|}{ Excitement } \\
\hline Baseline* & $16.2(5.1)$ & $13.7(4.8)$ & \multirow{3}{*}{$F=32.5, \mathrm{df}=2,54, p<0.001$} & \multirow{3}{*}{$F=4.39, \mathrm{df}=1,54, p=0.04$} & \multirow{3}{*}{$F=0.07, \mathrm{df}=2,54, p=\mathrm{NS}$} \\
\hline Month 3 & $9.6(5.2)$ & $7.3(2.9)$ & & & \\
\hline Month 6 & $8.4(4.6)$ & $7.7(4.1)$ & & & \\
\hline \multicolumn{6}{|c|}{ Depression/anxiety } \\
\hline Baseline $^{*}$ & $19.9(6.4)$ & $16.1(5.7)$ & \multirow{3}{*}{$F=23.8, \mathrm{df}=2,55, p<0.001$} & \multirow{3}{*}{$F=4.77, \mathrm{df}=1,55, p=0.03$} & \multirow{3}{*}{$F=1.8, \mathrm{df}=2,55, p=\mathrm{NS}$} \\
\hline Month 3 & $11.4(3.7)$ & $11.1(3.3)$ & & & \\
\hline Month 6 & $11(4.4)$ & $11.3(5.7)$ & & & \\
\hline \multicolumn{6}{|l|}{ Cognitive } \\
\hline Baseline $^{*}$ & $20.6(6.3)$ & $17.7(5.8)$ & \multirow{3}{*}{$F=37.05, \mathrm{df}=2,53, p<0.001$} & \multirow{3}{*}{$F=3.19, \mathrm{df}=1,53, p=\mathrm{NS}$} & \multirow{3}{*}{$F=0.1, \mathrm{df}=2,53, p=\mathrm{NS}$} \\
\hline Month 3 & $13(6.1)$ & $10.9(4.1)$ & & & \\
\hline Month 6 & $12(5.1)$ & $10.7(6.3)$ & & & \\
\hline
\end{tabular}

* Significant after Bonferroni correction time analysis.

3.5. Adherence to Treatment. Male adherence was above $95 \%$ during the followup. Females showed an inconsistent adherence to treatment and never outnumbered the male subjects. There were significant differences in week $6(N=45,95.7 \%$ versus $N=15,68.2 \%, X^{2}=10.03$, df $=1$, and $\left.p=0.002\right)$ and month $5\left(N=44,93.6 \%\right.$ versus $N=14,70 \%, X^{2}=6.73, \mathrm{df}=$ 1 , and $p=0.009)$ (Figure 1$)$. Adherence correlated with specific ROMI items in males (Table 5), while only a negative correlation was found between pressure/force to take medication and adherence to treatment in females $(r=-0.55, p=0.009)$.

\section{Discussion}

This study examined sex differences in clinical characteristics and treatment response of adolescents with schizophrenia, an age group on which there is a paucity of studies. The main results included a higher adherence to treatment in males and sex differences in the pattern of cognitive recovery.
The baseline assessment showed an earlier onset of illness in males, which is consistent with previous reports $[1,25,26]$. In contrast with adult studies [2], men showed a higher baseline score in the depression/anxiety factor and higher scores in the excitement factor. Both groups had a significant clinical improvement throughout the followup. Although nonstatistically significant, women showed a higher reduction in the negative factor, which could be related to the males' more severe negative symptoms reported in other follow-up studies $[8,27]$.

In the current study, female subjects showed a better performance in social cognition and attention/vigilance domains. Previous studies examining sex differences in cognitive development have shown contrasting results, mainly due to the use of different tests $[28,29]$. Studies also examining cognitive performance as measured by the MCCB in healthy adolescents reported sex differences in the reasoning and problem solving domain $[22,30]$. To the best of our 


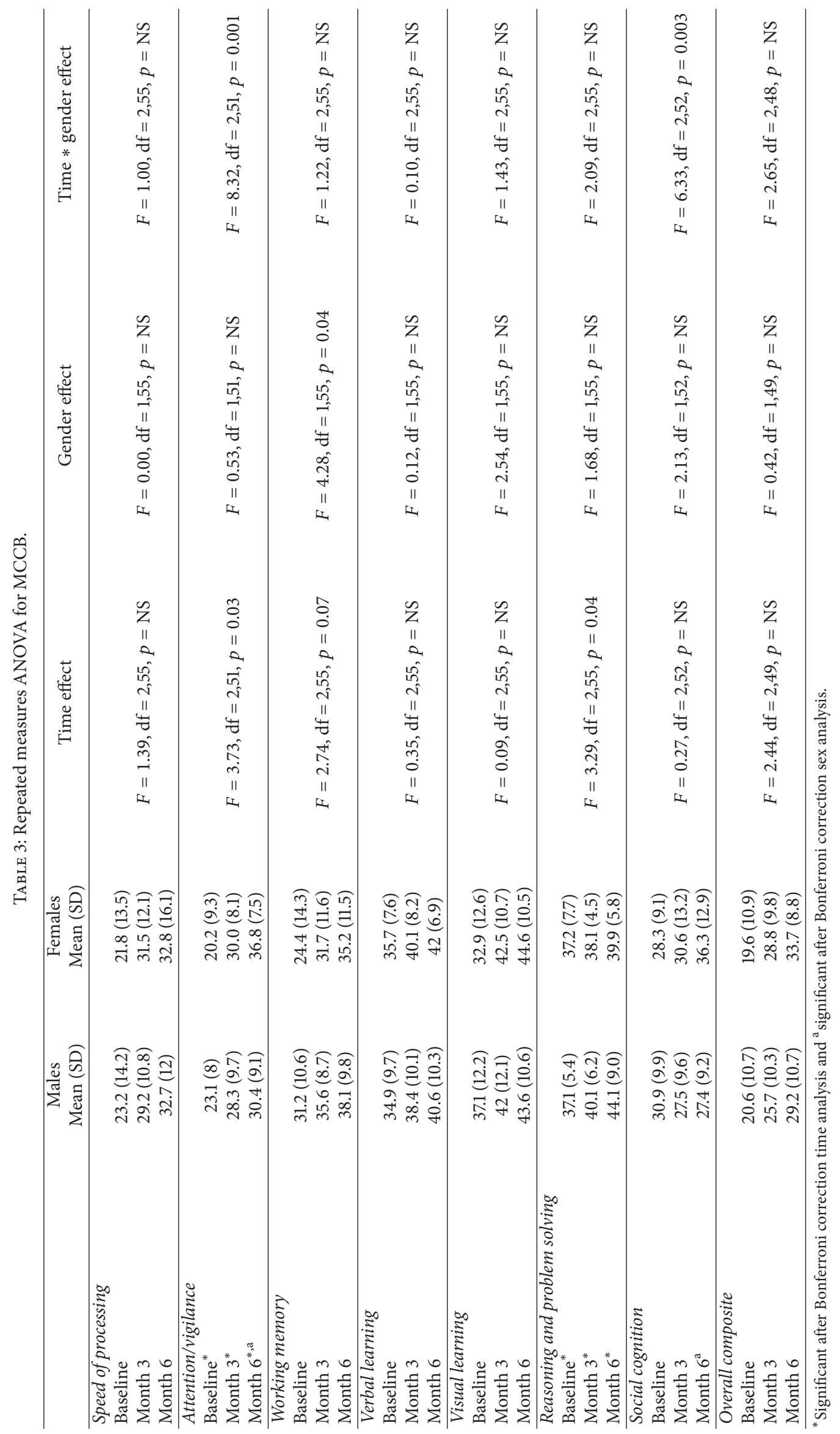


TABLE 4: Percentage of subjects showing a good functioning in the PSP subscales during the followup.

\begin{tabular}{|c|c|c|c|c|c|}
\hline & $\begin{array}{l}\text { Males } \\
N(\%)\end{array}$ & $\begin{array}{c}\text { Females } \\
N(\%)\end{array}$ & $X^{2}$ & $\mathrm{df}$ & $p$ \\
\hline \multicolumn{6}{|l|}{ Baseline } \\
\hline (1) Socially useful activities & $2(3.3)$ & $1(3.7)$ & 0.01 & 1 & 0.93 \\
\hline (2) Personal and social relationships & $3(5)$ & $1(3.7)$ & 0.07 & 1 & 0.79 \\
\hline (3) Self-care & $14(23.3)$ & $7(25.9)$ & 0.07 & 1 & 0.79 \\
\hline (4) Disturbing and aggressive behaviors & $24(40)$ & $20(74.1)$ & 8.65 & 1 & 0.01 \\
\hline \multicolumn{6}{|l|}{ Month 3} \\
\hline (1) Socially useful activities & $18(36)$ & $9(40.9)$ & 0.16 & 1 & 0.69 \\
\hline (2) Personal and social relationships & $17(34)$ & $7(31.8)$ & 0.03 & 1 & 0.86 \\
\hline (3) Self-care & $37(74)$ & $17(77.3)$ & 0.09 & 1 & 0.77 \\
\hline (4) Disturbing and aggressive behaviors & $42(84)$ & $19(86.2)$ & 0.07 & 1 & 0.80 \\
\hline \multicolumn{6}{|l|}{ Month 6} \\
\hline (1) Socially useful activities & $18(41.9)$ & $13(61.9)$ & 2.27 & 1 & 0.13 \\
\hline (2) Personal and social relationships & $14(32.6)$ & $12(57.1)$ & 3.54 & 1 & 0.06 \\
\hline (3) Self-care & $31(72.1)$ & $18(87.5)$ & 1.46 & 1 & 0.23 \\
\hline (4) Disturbing and aggressive behaviors & $38(88.4)$ & $19(90.5)$ & 0.06 & 1 & 0.8 \\
\hline
\end{tabular}

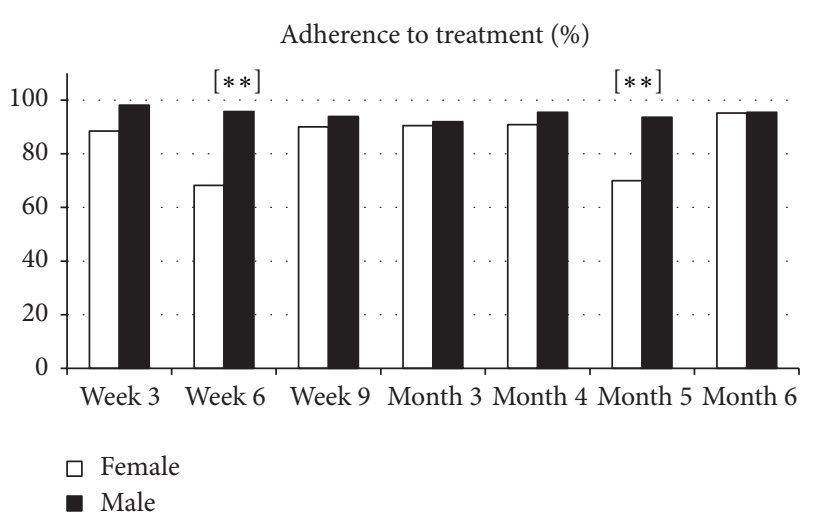

FIGURE 1: Comparative changes in percentage of adherence to treatment. ${ }^{* *} p<0.01$.

knowledge, this is the first study examining gender differences in adolescents with schizophrenia using the MCCB. The better performance of females in social cognition resembles that of adults, supporting the notion that cognitive development shows a strong improvement during childhood, a moderate improvement in adolescence, and only a slight improvement in late adolescence and young adulthood [31]. This could be in line with previous reports of a better performance in emotion recognition [32] and a lower reduction of amygdala and insula, brain structures mediating emotional and empathy processes in females [25]. The observed differences in the attention/vigilance domain could be explained by the poor performance that males exhibited during followup, reflecting the sustained attention deficits reported in patients with an early onset of the illness [33].

The baseline PSP scores showed that most patients were unable to perform socially useful activities and maintain social relationships. The higher percentage of males showing disturbing/aggressive behaviors was also reported in samples
TABLE 5: Correlation between the adherence to treatment and ROMI items in males.

\begin{tabular}{lccc}
\hline & Week 3 & Month 3 & Month 6 \\
\hline Males & & & \\
(1) Perceived benefit & - & $-0.3^{*}$ & - \\
(2) Positive relationship with clinician & - & $-0.33^{*}$ & - \\
(3) Positive relationship with therapist & - & - & - \\
(4) Positive family belief & $0.28^{*}$ & $0.36^{*}$ & - \\
(5) Relapse prevention & - & - & $0.31^{*}$ \\
(6) Pressure/force & $-0.3^{*}$ & - & - \\
(7) Fear of rehospitalization & - & $-0.39^{* *}$ & - \\
\hline
\end{tabular}

${ }^{*} p \geq 0.05 ;{ }^{* *} p \geq 0.01$.

of chronic adult outpatients [26]. Interestingly, both groups exhibited an improvement in all areas, in contrast with adult studies, where women reported a better occupational [34] and social functioning [35]. Present results could be explained by the use of PSP which evaluates particular areas of functioning instead of global functioning.

Male adherence to treatment was better and correlated with a positive family belief, which is in line with results of a study of the first episode of psychosis in adults showing that males received more help from their families, in particular in terms of health, psychotic symptoms, and psychological distress [36]. Future studies could determine whether the families' expectations vary according to the patient's gender and in turn influence the adherence to treatment.

\section{Limitations}

Present results should take into account the small sample size, the short followup, and the lack of evaluation of the family functioning or rearing practices that could provide 
more information about the psychosocial variables associated with functioning or adherence to treatment.

\section{Conclusions}

Male and female adolescents showed similar clinical presentation and functioning but a different pattern of cognitive improvement and adherence to treatment. Such factors should be considered in the long-term therapeutic programs for this age group.

\section{Competing Interests}

The authors declare that they have no competing interests.

\section{Acknowledgments}

Authors wish to thank Dr. Marcos Rosetti for the manuscript review.

\section{References}

[1] S. E. Bergen, C. T. O’Dushlaine, P. H. Lee et al., "Genetic modifiers and subtypes in schizophrenia: investigations of age at onset, severity, sex and family history," Schizophrenia Research, vol. 154, no. 1-3, pp. 48-53, 2014.

[2] K. M. Abel, R. Drake, and J. M. Goldstein, "Sex differences in schizophrenia," International Review of Psychiatry, vol. 22, no. 5, pp. 417-428, 2010.

[3] X. Y. Zhang, D. C. Chen, M. H. Xiu et al., "Gender differences in never-medicated first-episode schizophrenia and medicated chronic schizophrenia patients," Journal of Clinical Psychiatry, vol. 73, no. 7, pp. 1025-1033, 2012.

[4] A. Erol, G. Putgul, F. Kosger, and B. Ersoy, "Facial emotion recognition in schizophrenia: the impact of gender," Psychiatry Investigation, vol. 10, no. 1, pp. 69-74, 2013.

[5] A. Vaskinn, K. Sundet, C. Simonsen, T. Hellvin, I. Melle, and O. A. Andreassen, "Sex differences in neuropsychological performance and social functioning in schizophrenia and bipolar disorder," Neuropsychology, vol. 25, no. 4, pp. 499-510, 2011.

[6] R. Ayesa-Arriola, J. M. Rodriguez-Sanchez, E. Gomez-Ruiz, R. Roiz-Santiáñez, L. L. Reeves, and B. Crespo-Facorro, "No sex differences in neuropsychological performance in first episode psychosis patients," Progress in Neuro-Psychopharmacology and Biological Psychiatry, vol. 48, no. 1, pp. 149-154, 2014.

[7] T. P. Gilmer, C. R. Dolder, J. P. Lacro et al., "Adherence to treatment with antipsychotic medication and health care costs among medicaid beneficiaries with schizophrenia," The American Journal of Psychiatry, vol. 161, no. 4, pp. 692-699, 2004.

[8] A. Thorup, N. Albert, M. Bertelsen et al., "Gender differences in first-episode psychosis at 5-year follow-up-two different courses of disease? Results from the OPUS study at 5-year follow-up," European Psychiatry, vol. 29, no. 1, pp. 44-51, 2014.

[9] C. Gillberg, "Epidemiology of early onset schizophrenia," in Schizophrenia in Children and Adolescents, H. Remschmidth, Ed., pp. 43-59, Cambridge University Press, Cambridge, UK, 2001.
[10] M. D. De Bellis, M. S. Keshavan, S. R. Beers et al., "Sex differences in brain maturation during childhood and adolescence," Cerebral Cortex, vol. 11, no. 6, pp. 552-557, 2001.

[11] A. Riecher-Rössler and H. Häfner, "Gender aspects in schizophrenia: bridging the border between social and biological psychiatry," Acta Psychiatrica Scandinavica, vol. 102, no. 407, pp. 58-62, 2000.

[12] American Psychiatric Association, The Diagnostic and Statistical Manual of Mental Disorders, DSM-IV, Washington, DC, USA, 1994.

[13] D. V. Sheehan, Y. Lecrubier, K. H. Sheehan et al., "The MiniInternational Neuropsychiatric Interview (M.I.N.I.): the development and validation of a structured diagnostic psychiatric interview for DSM-IV and ICD-10," Journal of Clinical Psychiatry, vol. 59, supplement 20, pp. 22-33, 1998.

[14] V. Peralta and M. J. Cuesta, "Validación de la escala de los síndromes positivo y negativo (PANSS) en una muestra de esquizofrénicos españoles," Actas Luso-Españolas de Neurología, Psiquiatría y Ciencias Afines, vol. 22, no. 4, pp. 171-177, 1994.

[15] R. S. Wallwork, R. Fortgang, R. Hashimoto, D. R. Weinberger, and D. Dickinson, "Searching for a consensus five-factor model of the positive and negative Syndrome Scale for schizophrenia," Schizophrenia Research, vol. 137, no. 1-3, pp. 246-250, 2012.

[16] A. Fresán, C. De La Fuente-Sandoval, C. Loyzaga et al., "A forced five-dimensional factor analysis and concurrent validity of the Positive and Negative Syndrome Scale in Mexican schizophrenic patients," Schizophrenia Research, vol. 72, no. 2-3, pp. 123-129, 2005.

[17] P.-L. Morosini, L. Magliano, L. Brambilla, S. Ugolini, and R. Pioli, "Development, reliability and acceptability of a new version of the DSM- IV Social Occupational Functioning Assessment Scale (SOFAS) to assess routine social functioning," Acta Psychiatrica Scandinavica, vol.101, no. 4, pp. 323-329, 2000.

[18] R.-E. Ulloa, R. Apiquian, G. Victoria, S. Arce, N. González, and L. Palacios, "Validity and reliability of the Spanish version of the personal and social performance scale in adolescents with schizophrenia," Schizophrenia Research, vol. 164, no. 1-3, pp. 176-180, 2015.

[19] E. Sabate, WHO Adherence Meeting Report, World Health Organization, Geneva, Switzerland, 2001.

[20] P. Weiden, B. Rapkin, T. Mott et al., "Rating of medication influences (ROMI) scale in schizophrenia," Schizophrenia Bulletin, vol. 20, no. 2, pp. 297-310, 1994.

[21] K. H. Nuechterlein, M. F. Green, R. S. Kern et al., "The MATRICS consensus cognitive battery-part 1: test selection, reliability, and validity," American Journal of Psychiatry, vol. 165, no. 2, pp. 203-213, 2008.

[22] G. C. Nitzburg, P. DeRosse, K. E. Burdick, B. D. Peters, C. B. Gopin, and A. K. Malhotra, "MATRICS cognitive consensus battery (MCCB) performance in children, adolescents, and young adults," Schizophrenia Research, vol. 152, no. 1, pp. 223228, 2014.

[23] A. Holmén, M. Juuhl-Langseth, R. Thormodsen, I. Melle, and B. R. Rund, "Neuropsychological profile in early-onset schizophrenia-spectrum disorders: measured with the MATRICS battery," Schizophrenia Bulletin, vol. 36, no. 4, pp. 852-859, 2010.

[24] I. Kelleher, A. Murtagh, M. C. Clarke, J. Murphy, C. Rawdon, and M. Cannon, "Neurocognitive performance of a community-based sample of young people at putative ultra high 
risk for psychosis: support for the processing speed hypothesis," Cognitive Neuropsychiatry, vol. 18, no. 1-2, pp. 9-25, 2013.

[25] A. Mendrek and A. Mancini-Marie, "Sex/gender differences in the brain and cognition in schizophrenia," Neuroscience \& Biobehavioral Reviews, vol. 67, pp. 57-78, 2016.

[26] B. Carpiniello, F. Pinna, M. Tusconi, E. Zaccheddu, and F. Fatteri, "Gender differences in remission and recovery of schizophrenic and schizoaffective patients: preliminary results of a prospective cohort study," Schizophrenia Research and Treatment, vol. 2012, Article ID 576369, 8 pages, 2012.

[27] S. Galderisi, P. Bucci, A. Üçok, and J. Peuskens, "No gender differences in social outcome in patients suffering from schizophrenia," European Psychiatry, vol. 27, no. 6, pp. 406-408, 2012.

[28] A. Ardilla, M. Rosselli, E. Matute adn, and O. Inozemtseba, "Gender differences in cognitive development," Developmental Psychology, vol. 47, no. 4, pp. 984-990, 2011.

[29] J. H. Kramer, E. Kaplan, D. C. Delis, L. O’Donnell, and A. Prifitera, "Developmental sex differences in verbal learning," Neuropsychology, vol. 11, no. 4, pp. 577-584, 1997.

[30] W. S. Stone, R. I. Mesholam-Gately, A. J. Giuliano et al., "Healthy adolescent performance on the MATRICS consensus cognitive battery (MCCB): developmental data from two samples of volunteers," Schizophrenia Research, vol. 172, no. 1-3, pp. 106113, 2016.

[31] C. B. Romine and C. R. Reynolds, "A model of the development of frontal lobe functioning: findings from a meta-analysis," Applied Neuropsychology, vol. 12, no. 4, pp. 190-201, 2005.

[32] J. Ramos-Loyo, L. Mora-Reynoso, L. M. Sánchez-Loyo, and V. Medina-Hernández, "Sex differences in facial, prosodic, and social context emotional recognition in early-onset schizophrenia," Schizophrenia Research and Treatment, vol. 2012, Article ID 584725, 12 pages, 2012.

[33] T. P. Zahn, L. K. Jacobsen, C. T. Gordon, K. McKenna, J. A. Frazier, and J. L. Rapoport, "Attention deficits in childhoodonset schizophrenia: reaction time studies," Journal of Abnormal Psychology, vol. 107, no. 1, pp. 97-108, 1998.

[34] E. Ceskova and R. Prikryl, "Importance of gender in the treatment of schizophrenia," Primary Care Companion to the Journal of Clinical Psychiatry, vol. 14, no. 6, 2012.

[35] R. Segarra, N. Ojeda, A. Zabala et al., "Similarities in early course among men and women with a first episode of schizophrenia and schizophreniform disorder," European Archives of Psychiatry and Clinical Neuroscience, vol. 262, no. 2, pp. 95-105, 2012.

[36] M. Bertani, A. Lasalvia, C. Bonetto et al., "The influence of gender on clinical and social characteristics of patients at psychosis onset: a report from the Psychosis Incident Cohort Outcome Study (PICOS)," Psychological Medicine, vol. 42, no. 4, pp. 769-780, 2012. 


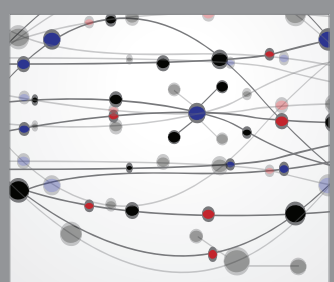

The Scientific World Journal
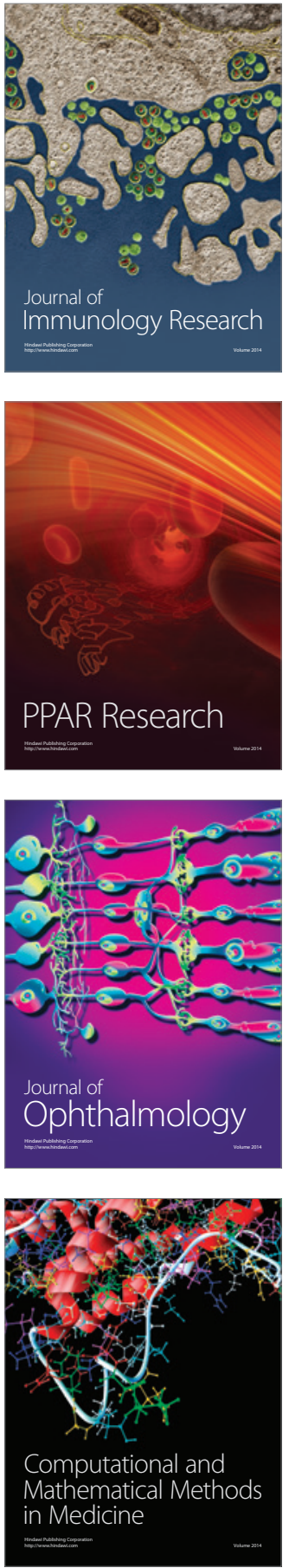

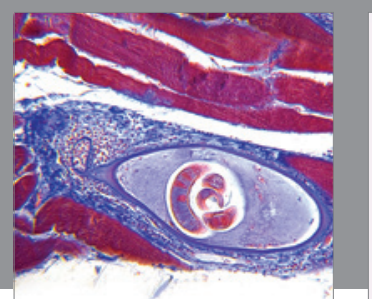

Gastroenterology Research and Practice

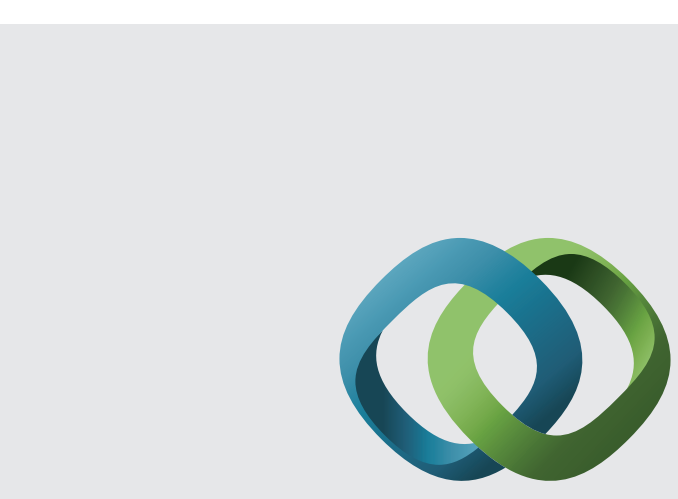

\section{Hindawi}

Submit your manuscripts at

http://www.hindawi.com
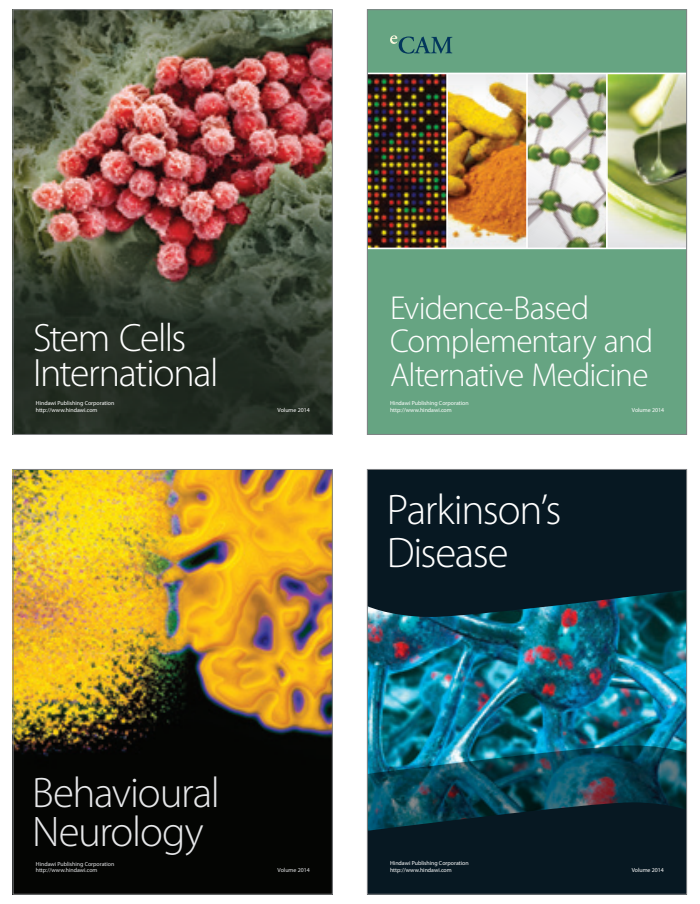
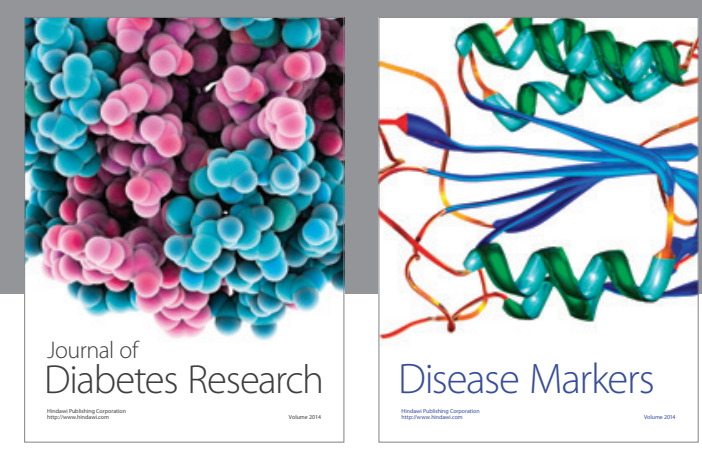

Disease Markers
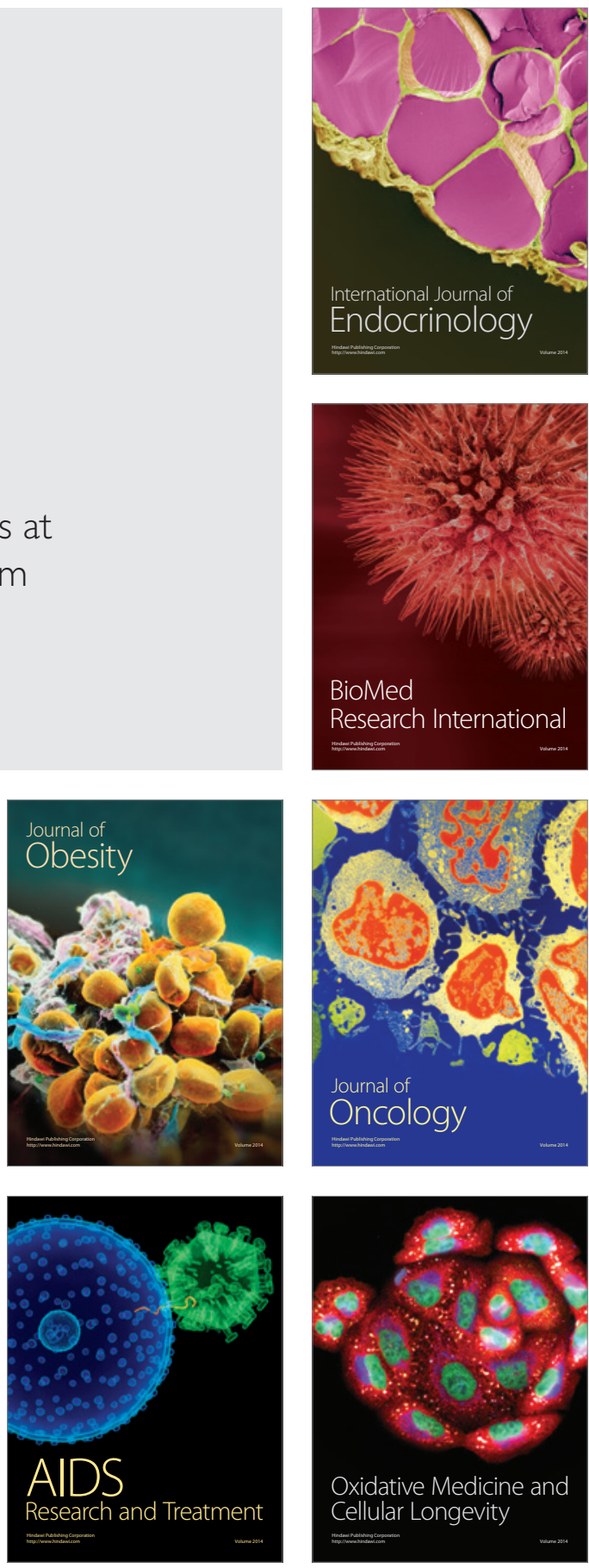